\title{
GEOPOLÍTICAS DEL ESPÍRITU. ONTOLOGÍAS PENTECOSTALES Y GOLPE DE ESTADO EN HONDURAS
}

\author{
SPIRIT-FILLED GEOPOLITICS. PENTECOSTAL ONTOLOGIES \\ AND THE HONDURAN COUP
}

William Girard

Recibido: 12/08/2019 - Aceptado: 11/10/2019

\begin{abstract}
Resumen
Situado en Copán Ruinas, este artículo describe el papel que jugó la ontología cristiana pentecostal en el gran apoyo que tuvo el golpe de Estado que derrocó al presidente de izquierda, Manuel Zelaya, en 2019. Conceptualmente se ancla en la línea de pensamiento académica sobre la política de algunos movimientos indígenas en Latinoamérica y en su divergencia con los marcos "políticos" modernos, para argumentar que el pentecostalismo tiene un marco de acción político no moderno que es similar. Esta modalidad de política pentecostal -que denomino "geopolítica del espíritu"-, entre otros elementos no modernos, tiene una temporalidad apocalíptica y unos dominios integrados de lo "sobrenatural"/político.

Palabras clave: Centroamérica, cristianismo, Guerra Fría, geografía, Honduras, ontología.

Abstract

Set in the town of Copan Ruinas, Honduras, this article describes the role of Pentecostal Christians' ontology in their broad support for the 2009 coup, which overthrew the left-leaning president, Manuel Zelaya. It draws on recent scholarship that considers how the political engagement of some indigenous movements in Latin America diverge from modern framings of "politics" in order to argue that Pentecostals similarly engage in a nonmodern mode of political action. Among other nonmodern elements, this mode of Pentecostal politics -which I term "spirit-filled geopolitics"- includes both an apocalyptic temporality and integrated "supernatural"/ political domains.
\end{abstract}

Keywords: Central America, Christianity, Cold War, geography, Honduras, ontology. 


\section{Introducción}

Durante el verano de 2006 estuve conversando sobre un montón de tonterías con James, un amistoso belga dueño de un popular restaurante de Copán Ruinas, Honduras. Pero en el corazón de nuestras permanentes discusiones una pregunta quedaba sin respuesta: ¿cuál de los dos jugaba mejor al Risk? Después de hablarlo por semanas, acordamos jugar para resolver el problema.

El tablero de Risk consiste en un mapa del mundo dividido en regiones o "territorios". Cuando el juego va a comenzar, los jugadores reciben pequeños "ejércitos" de plástico. Acto seguido, piden territorios y ponen sus respectivos ejércitos encima. Una vez se han seleccionado todos los territorios, los jugadores "invaden" los de los otros, con el objetivo final de conquistar el mundo.

Apenas comenzamos a jugar, Ramón, un miembro de una Iglesia pentecostal del sector, nos vio desde la calle y se fue directo hacia nosotros. Yo había vivido en Copán intermitentemente desde el 2000. Sin embargo, Copán solo se había convertido en el lugar de mi investigación el mes anterior, cuando empecé el trabajo de campo preliminar con la comunidad pentecostal que estaba en rápida expansión. Como en muchas partes del mundo, en los últimos treinta años el pentecostalismo había crecido notoriamente en la ciudad. En ese lapso de tiempo, el porcentaje de copanecos identificados como pentecostales pasó de tener un solo dígito al 30-40 por ciento ${ }^{1}$ de los ocho mil habitantes de la ciudad.

Cuando Ramón llegó a nuestra mesa, nos saludó con una sonrisa y, después de charlar un poco, nos preguntó sobre el juego. James le explicó las reglas básicas:

\section{"Entonces, ies como el monopolio?" Preguntó Ramón.}

"Sí, como el monopolio", respondió James.

"Pero, ies un juego de guerra?"

"Si, de guerra", respondió James, "Buscas convertirte en el país más poderoso del mundo". "Ahhh", dijo Ramón, escaneando el tablero. "¿Dónde está Israel?"

Quedé desconcertado. Si buscaba al país más poderoso y de mayor importancia estratégica, parecería obvio que ese país sería Estados Unidos.

En ese verano comprendí que para esa comunidad de cristianos Israel pronto se convertiría en el principal escenario de los Últimos Días, bíblicamente profetizados, y, como fruto del amor perdurable de Dios por el pueblo judío, en la nación más poderosa del mundo. Que algunos cristianos insistan en el fuerte afecto de Dios hacia los creyentes en una fe diferente a la suya podría sonar incongruente. Pero esos sentimientos y la doctrina que los abarca -llamada sionismo cristiano- son acogidos por un gran número de pentecostales y evangélicos en todo el mundo. No todos los pentecostales de Copán son cristianos sionistas, pero sí la mayoría. 
En mi trabajo de campo extendido aprendí que esta visión geopolítica pentecostal también está sumergida en una división hemisférica entre los países con gobiernos de derecha y los de la "marea rosa". Los primeros son descritos como receptores de bendiciones por permanecer en el camino de Dios y los otros como un duradero castigo por desviarse de sus deseos. Si bien los pentecostales en Copán nunca usaron el término, debido a las diversas formas en que combinan el sentido común geopolítico secular y la agencia "sobrenatural", yo llamo a este modo pentecostal de participación global "geopolítica del espíritu". De manera general, este artículo ${ }^{2}$ sostiene que entender la (geo)política pentecostal implica entender la ontología pentecostal. En los términos de estos cristianos ambas cosas son indivisibles. Para sostener tal argumento, examino el rol de la geopolítica del espíritu a través de las respuestas de los pentecostales copanecos al golpe de Estado de Honduras de 2009. La tarde que jugamos Risk faltaban tres años para aquel evento.

Había comenzado mi temporada de dieciocho meses de trabajo de campo en Copán cuando los militares hondureños dieron el golpe de Estado. Esto significó que fui testigo de las diversas respuestas de los copanecos inmediatamente después del exilio del presidente, Manuel "Mel” Zelaya, y en el mediano plazo. Mi investigación se basó, en gran medida, en la observación participante en tres iglesias pentecostales. Asistí a servicios y a grupos de estudio bíblico, y acompañé a algunos miembros de la iglesia en tres retiros, cada uno de los cuales duró entre cinco y siete días. También pasé mucho tiempo con los pentecostales por fuera de los eventos relacionados con la iglesia, ya fuera cenando en sus casas, viendo películas cristianas, celebrando fiestas de cumpleaños o charlando en el parque central. Adicionalmente, hice más de sesenta entrevistas informales a pentecostales y no pentecostales.

Después del golpe de Estado, los pentecostales solían describir la existencia de Honduras como un espacio liminal establecido entre las dos fuerzas que la Biblia predice surgirán durante los últimos tiempos: el camino de la luz y el camino de la oscuridad. Para estos cristianos, el último era inequívocamente la "marea rosa", mientras que el primero incluía a Israel y a los países latinoamericanos con gobiernos de derecha. En su opinión, Zelaya había llevado el país hacia la izquierda, lejos de los deseos de Dios, pero con Su ayuda los pentecostales guiarían a Honduras por el camino de regreso a la luz.

Más allá de los eventos descritos, este artículo tiene en cuenta la importancia de la ontología no moderna y del espíritu de los pentecostales, de cara al panorama político de la Latinoamérica contemporánea. Durante el trabajo de campo descubrí que la diferencia entre el pentecostalismo y mi propio secularismo no era solo cuestión de dos perspectivas distintas sobre el mismo mapa (por ejemplo, Israel en lugar de Estados Unidos como centro del poder geopolítico), sino también de los diferentes "mundos [que estaban siendo] vistos" (Viveros de Castro 11). 
Figura 1

RIGHTLY DIVIDING THE WORD OF TRUTH, 1918

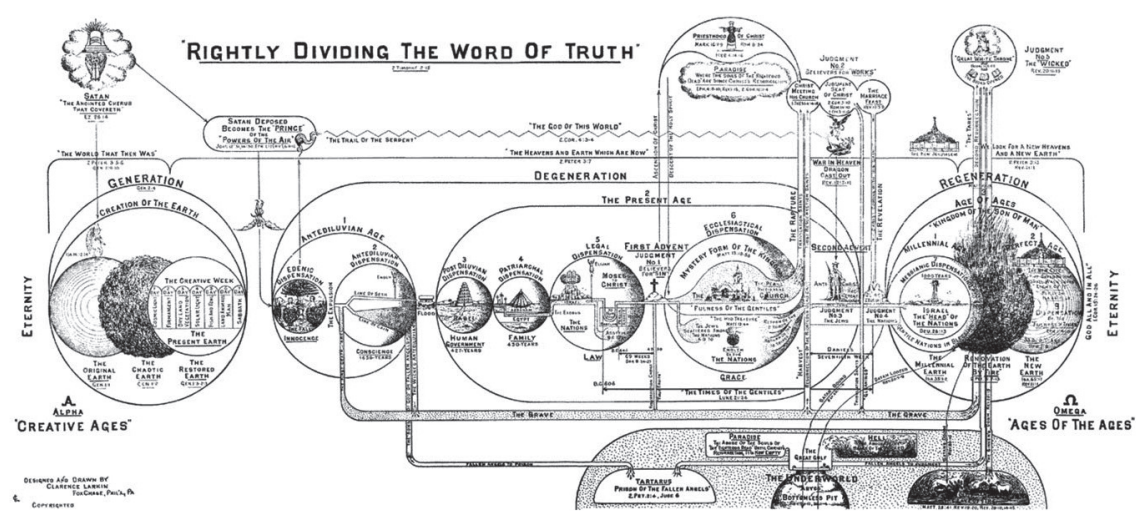

Fuente: Con permiso del reverendoLarkin Estate. Clarence Larkin, The Greatest Book on “Dispensational Truth" in the World (1918; reimpreso en Philadephia, PA: Rev. Clarence Larkin Est., 1920).

Para enmarcar estas diferencias es útil enfocarse en las distintas "constituciones" que gobiernan los dos mundos interconectados. Dentro de la constitución moderna los "seres sobrenaturales" están aislados de la política. Solo los humanos cuentan como actores políticos (Latour). Sin embargo, dentro de la constitución no moderna de los pentecostales, una gran cantidad de agentes "sobrenaturales" (por ejemplo, Dios o los demonios) también son actores políticos inmanentes. Los demonios corrompen a los líderes políticos. Dios provee abundantes recursos naturales a las naciones que lo merecen. Los políticos se alían con el diablo (a sabiendas o sin saberlo) cuando abrazan la política de izquierda. Esta amplia gama de actores políticos también crea modos de acción política humana. Con el fin de transformar su país, los pentecostales hondureños trabajan para asegurar el apoyo de Dios y para desterrar a los demonios a través de la oración y la guerra espiritual. ${ }^{3}$

Los mapas de la geopolítica del espíritu no solo son espaciales, sino también temporales. Esta dimensión temporal se arraiga en el dispensacionalismo premilenial, un esquema basado en la Biblia que divide la totalidad del tiempo (desde que Dios creó el universo hasta su fin) en siete dispensaciones. Según la mayoría de los cronogramas dispensacionalistas, el mundo está atravesando el final de la dispensación eclesiástica (que comenzó con la muerte y resurrección de Jesús) y se está acercando rápidamente a la tribulación (los días violentos antes del regreso de Jesús). A diferencia del tiempo vacío y homogéneo de la geopolítica secular (Anderson), dentro de la geopolítica del espíritu el mundo se encamina hacia una dirección apocalíptica específica que Dios ha ordenado y cuyos signos son evidentes para cualquiera que sepa dónde buscarlos (Figura 1). 
La presencia de agentes "sobrenaturales" dentro de la política pentecostal recuerda a los "actores extraños" (De la Cadena, 2010) dentro de la política indígena latinoamericana contemporánea. ${ }^{4}$ De hecho, Escobar y De la Cadena (2010) argumentan que algunas circunscripciones dentro del "giro a la izquierda", sobre todos las indígenas y las de los movimientos sociales afrodescendientes, divergen no solo del neoliberalismo, sino, incluso, de la modernidad. Como ejemplo de esta ruptura, tanto Escobar como De la Cadena (2010) resaltan la constitución ecuatoriana de 2008, que otorga derechos a "la naturaleza o la Pachamama". Explica Escobar: "Más allá de ser un reflejo de la sabiduría ambiental, la Pachamama es una entidad extraña que no encaja fácilmente en la estructura filosófica de una constitución moderna; la noción es impensable dentro de cualquier perspectiva moderna" (39). Mientras tanto, De la Cadena (2010) sostiene que la inclusión de entidades no humanas en la constitución revela "que la política indígena puede superar a la política como la conocemos" (335). El presente artículo sugiere que la política pentecostal también "supera a la política como la conocemos". Tomando como punto de partida la geopolítica del espíritu, este trabajo plantea que la ruptura con las ontologías modernas no solo está teniendo lugar dentro (de segmentos) de la izquierda latinoamericana, sino también dentro (de segmentos) de la derecha.

Si bien el Espíritu Santo no aparece en ninguna constitución nacional, la geopolítica del espíritu está vinculada al Estado, tanto en los Estados Unidos como en Honduras. Para describir estos vínculos, ahondo en el análisis De la Cadena (2010) de la cosmopolítica indígena como "parcialmente conectada" (Strathern) con las prácticas del Estado nacional secular. Como explica De la Cadena, las conexiones parciales "se refieren a una relación compuesta de agregados" que "no crean una entidad única". Observa: "la entidad que resulta es más de una, pero menos de dos" $(2010,347)$. Es decir, a pesar de la serie de vínculos, las entidades que surgen como resultado de mundos parcialmente conectados nunca se fusionan en una sola unidad. Más bien, se adhieren a lo que Strathern denomina un "circuito de conexiones" (54). De esta manera, la geopolítica del espíritu emerge a través de: una serie de vínculos entre supuestos y preocupaciones geopolíticas específicas, seculares y estatales (por ejemplo, las naciones como unidades independientes, la división binaria entre amigos y enemigos externos y la preocupación por las fronteras nacionales); y de marcos pentecostales (dispensacionalismo y agentes políticos "sobrenaturales"). La sección final de este artículo describe cómo la geopolítica secular (especialmente la geopolítica de la Guerra Fría) y la geopolítica del espíritu emergen de un "circuito de conexiones", es decir, "más de uno, menos de dos".

Además de describir cómo la política pentecostal "supera a la política como la conocemos" (De la Cadena, 2010, 335), tomar la geopolítica del espíritu como punto de partida permite explicar porque estos cristianos tienden a oponerse a los gobiernos de izquierda, y de inclinación a la izquierda, en Latinoamérica. Los antropólogos que 
han estudiado la región a menudo asumen que la tendencia pentecostal a favorecer la política conservadora y antiizquierda es resultado de la "afinidad electiva" del protestantismo (Weber 2002 [1905]) con el capitalismo, o una resonancia entre la ideología neoliberal y la orientación de los pentecostales hacia la superación personal y la moral individual. Esas conexiones entre las sensibilidades pentecostales y el capitalismo neoliberal ciertamente influyeron en el apoyo al golpe contra Zelaya, quien, según ellos, promovía una economía "colectivista" en contra del libre mercado. Sin embargo, su mapeo de las fuerzas políticas internacionales y el lugar de Honduras dentro de ellas, basados en la Biblia y en la geopolítica del espíritu, fueron notorias en los sermones, conversaciones, oraciones y prácticas pentecostales que presencié en el Copán antes y después del golpe. Por lo tanto, entender por qué las opiniones políticas de los pentecostales a menudo se alinean con la derecha en Latinoamérica implica tomarse en serio el mundo que habitan y no apresurarse a reducir ese mundo a la mera dinámica del neoliberalismo.

Si bien puede parecer poco convencional que las investigaciones relacionadas con los pentecostales mestizos se basen en marcos teóricos generados para comprender las consecuencias políticas de las ontologías indígenas, creo que existen buenas razones para hacerlo. En primer lugar, y en mi opinión, "funciona". El enfoque de De la Cadena (2010) proporciona una constelación de teorías que me permitieron desarrollar una explicación clara de lo que experimenté en Copán. En segundo lugar, su análisis de la multiplicidad ontológica de la izquierda latinoamericana me permite articular los intereses políticos de una multiplicidad ontológica similar, pero de derecha.

Finalmente, este movimiento también hace un importante aporte a la discusión general sobre las consecuencias políticas de las ontologías no modernas en la región. Debido a que esta corriente académica se ha centrado, en gran medida, en los pueblos indígenas marginados, ha habido una tendencia a asociar las ontologías no modernas con la resistencia política. De hecho, tanto De la Cadena (2010) como Escobar parecen tener mucho entusiasmo en las posibilidades que abre una ontología política no moderna para Latinoamérica. Comparto ese entusiasmo. Sin embargo, como la geopolítica del espíritu lo demuestra, las ontologías no modernas no necesariamente son más deseables (al menos desde la perspectiva de la izquierda) que sus contrapartes modernas. Incluir las ontologías pentecostales en la discusión reconoce la necesidad de darle una mayor atención a la amplia gama de proyectos políticos que involucran ontologías no modernas.

\section{Golpe de Estado en Honduras en 2009}

Mel Zelaya, miembro del Partido Liberal, recién se había convertido en el presidente de Honduras aquel día de 2006 en que jugamos Risk. La mayoría de los hondureños asumieron que Zelaya mantendría las políticas de centro-derecha que 
caracterizaron a los dos partidos políticos dominantes desde que el gobierno militar finalizó, a principios de los ochenta. Sin embargo, a los dos años de su mandato, Mel se alineó con la "marea rosa": aumentó el salario mínimo en un 60 \% y se unió al programa Petrocaribe y a la Alternativa Bolivariana para las Américas (ALBA), ambos liderados por Venezuela.

Cuando en marzo de 2009 volví a Copán para hacer mi trabajo de campo extendido, los periódicos estaban atestados de historias sobre la propuesta más reciente de Mel: una votación nacional para determinar si era necesario convocar a una Asamblea Nacional Constituyente que permitiera reescribir la constitución, una iniciativa conocida como la cuarta urna. Zelaya era enfático en que de la Asamblea saldría una constitución que serviría a las comunidades más pobres y marginadas del país. Los opositores de Mel, entre los que estaba casi toda la clase política de los dos partidos políticos principales (incluidos los suyos), los líderes empresariales y la mayoría de los medios de comunicación hondureños, argumentaron que la cuarta urna no solo era ilegal, sino que también era una táctica velada para eliminar el límite constitucional de un solo periodo presidencial, lo que posibilitaría que Zelaya se postulara a un segundo mandato. Estos grupos también insistieron en que Mel era un títere de Hugo Chávez y que la cuarta urna era simplemente el último intento del presidente venezolano (junto con Petro Caribe y ALBA) para entrometerse en los asuntos de Honduras. Para reforzar el apoyo popular a su iniciativa, Zelaya quiso llamar a un plebiscito nacional no vinculante para preguntar si la cuarta urna debería tener lugar.

En la mañana del 28 de junio de 2009, día programado para el plebiscito no oficial, soldados del ejército hondureño asaltaron la residencia de Zelaya, lo detuvieron e inmediatamente lo sacaron del país. Las figuras públicas que apoyaron el exilio de Zelaya afirmaron que su búsqueda incansable de la cuarta urna obligó a los líderes civiles y militares a tomar esas medidas drásticas. Roberto Micheletti, miembro del Partido Liberal, el mismo de Zelaya, y jefe del Congreso Nacional de Honduras (el siguiente en el mandato constitucional en la línea para reemplazar al presidente), juró como presidente. Pronto se llevaron a cabo enormes manifestaciones en todo el país que apoyaban el golpe de Estado y, a los pocos días, el Frente Nacional de Resistencia Popular (FNRP), una coalición de organizaciones de base y movimientos sociales, también se tomó las calles con protestas masivas que exigían el regreso de Zelaya.

Pasé esos días inciertos tratando de comprender las reacciones de los copanecos a tantos eventos extraordinarios. Había opiniones encontradas sobre Zelaya, tal como había descubierto en los meses previos al golpe, y las grandes categorías socioeconómicas poco ayudaban a predecir las opiniones de las personas. Las afirmaciones de que el exilio de Mel había salvado al país de una dictadura comunista dominada por Chávez, provenían tanto de la población adinerada como de aquella que luchaba por sobrevivir. Esa opinión, alimentada por los medios de comunicación nacionales de derecha y por la clase política, fue, de hecho, la más común. Otros, incluidos 
algunos copanecos de clase media, expresaron una profunda tristeza y frustración porque, según explicaron, los oligarcas del país habían expulsado al único presidente hondureño que se había preocupado por los pobres. Para otros, en todas las clases, no había nada especial en Zelaya: era simplemente un político tan corrupto y deshonesto como el resto. A sus ojos, el golpe era otro ejemplo de cómo las élites luchan entre sî por el poder y la riqueza mientras los pobres sufren las consecuencias. Sin embargo, aunque la clase no fue un factor que determinara las opiniones de los copanecos sobre Mel y el golpe, otro factor jugó un papel decisivo: casi todos los pentecostales que conocía apoyaron la destitución de Zelaya.

\section{Una constitución pentecostal}

Este relato del golpe de Estado se adhiere a los mandatos de la constitución moderna, en la que solo los humanos cuentan como actores políticos (Latour). Cualquier actor "sobrenatural" a priori queda excluido de la política. Sin embargo, en Copán, las descripciones pentecostales de estos eventos poco tuvieron en cuenta ese principio de la constitución moderna. Dentro de sus narraciones, las entidades "sobrenaturales" -Dios, los ángeles, el diablo y los demonios- también actuaron en la política nacional e internacional. Sin ir muy lejos de la cosmopolítica indígena que describe De la Cadena (2010), su forma de entender el golpe "supera[superó] a la política como la conocemos".

Esa constitución no moderna fue clave para el análisis de la geopolítica del espíritu y para las prácticas concomitantes que ocurrieron en el grupo de estudio bíblico al que asistí poco después del golpe. Fueron momentos de mucha tensión porque nadie estaba seguro de lo que le esperaba al país. Rumores recorrían Honduras. ¿Habría una guerra civil?, ¿invadiría Chávez a Honduras para posesionar nuevamente a Zelaya como presidente (como, de hecho, amenazó con hacer)? De ser así, ¿entrarían los militares estadounidenses a Honduras para oponerse a él?

Cuando llegué a la casa del hermano Nelson, un cómodo espacio de clase media, en lugar de los alegres saludos que generalmente intercambiábamos, me uní al grupo con un ligero movimiento de cabeza y rápidamente ubiqué un asiento libre. Pronto el hermano Nelson se levantó de su silla para comenzar la reunión. Nos recordó, respirando profundamente, que el pastor y el liderazgo de la iglesia habían prestado mucha atención a la relación de Honduras con los países socialistas de Latinoamérica durante la administración de Zelaya, preguntándose si eso representaba un problema para Honduras. El mayor problema era si estas alianzas pondrían a Honduras en contra de los caminos de Dios. Continuó:

Entonces eso era lo que Honduras no le convenía al final, que lo pusieran en contra de Israel, el pueblo escogido de Dios para Honduras. Que nosotros como hondureños queremos a este país, en el que Dios nos ha puesto, y también tenemos un amor por Israel, a quien el Señor nos dice 
así, como una orden, diciéndonos pedir por la paz de Jerusalén y al final Honduras llegar a una situación de estar en contra del pueblo de Dios. Pero entonces nosotros vamos a pedir por la paz de Jerusalén y también hoy vamos a pedir por la paz de Honduras, verdad para que sea Dios que de paz a nuestra nación.

Después el grupo se puso de pie y, con los brazos alzados al cielo, rogaron a Dios que llevara la paz a Israel para que hubiera paz en Honduras.

Antes de examinar cómo este esfuerzo geopolítico del espíritu "supera a la política como la conocemos", deberíamos entender cómo este evento se enmarca dentro de la "política como la conocemos". Recientemente, antropólogos interesados en las consecuencias políticas del pentecostalismo en la región, se han enfocado en los vínculos entre la fe pentecostal y el neoliberalismo. Según esos análisis, el punto crítico de conexión entre el pentecostalismo y la política neoliberal yace en el reino de la (falsa) conciencia. Es decir, de acuerdo con la insistencia de la constitución moderna en que las acciones de Dios en el mundo deben limitarse al "corazón de corazones" (Latour) de los individuos -las creencias u otros modos de vida interior-, el significado político del pentecostalismo se enmarca como una ideología. Esta línea académica describe al pentecostalismo como una instancia de una ideología que oculta o minimiza las fuerzas sociales neoliberales y los actores que hacen precaria la vida en la Centroamérica contemporánea.

Esa literatura tiende a entender las consecuencias de la fe pentecostal en términos similares, y describe su ideología de dos maneras: como opio y como individualización. Paro lo primero dice que el pentecostalismo da a sus partidarios estabilidad psicológica y bienestar de cara a los mundos sociales cambiantes y difíciles desatados por las políticas económicas neoliberales. Por ejemplo, Pine sostiene que el pentecostalismo ofrece a los trabajadores de la maquila "la sensación de que la disciplina con la que viven [en las fábricas] es de su propia elección", ${ }^{5}$ y la capacidad de "encontrar consuelo" pese a la "absoluta falta de control sobre sus condiciones de trabajo" (Pine 2008: 166; énfasis mío). Para lo segundo destaca la individualización, un proyecto compartido por el pentecostalismo y el neoliberalismo. En este sentido, O’Neill (2010) describe cómo los pentecostales guatemaltecos ejercen una "ciudadanía cristiana", es decir, realizan una serie de esfuerzos individuales e interiorizados -rezar, ayunar y examinar sus propias conciencias- para superar cualquier cantidad de males sociales. ${ }^{6}$

Ya sea como opio o como instrumento de individualización, las consecuencias políticas de estas transformaciones interiores se entienden en su capacidad de reducir la conciencia de los individuos sobre las fuerzas y actores neoliberales. En tanto opio se dice que el pentecostalismo acostumbra a sus seguidores a la brutalidad de la vida neoliberal, lo que hace menos probable que se resistan a ella. En tanto individualización, esta tradición describe la ideología pentecostal como una desviación, pues enfoca la atención de sus seguidores en los comportamientos morales individuales, en lugar 
de en las "raíces estructurales" del neoliberismo (Pine 169), o en "el Estado nación, las corporaciones multinacionales y el crimen organizado" (O'Neill, 2010, 4).7

La predicación de Nelson de esa noche encuadra fácilmente con estas explicaciones: como una cobertura ideológica para los intereses económicos neoliberales de la élite hondureña que destituyó a Zelaya, o como un consuelo en un momento de cambio dramático. Entender así los comentarios de Nelson, o la política pentecostal en general, no es algo necesariamente incorrecto. Sin embargo, traduce demasiado rápidamente los mundos pentecostales a los términos de la constitución moderna y reduce las consecuencias políticas del pentecostalismo a las meras formas en que complementa la economía neoliberal y las formas de gobierno neoliberales. En el proceso, esta perspectiva pasa por alto el papel de los "mundos que están siendo vistos" por los pentecostales, es decir, aquellos mundos que no solo son producidos por los intereses y maquinaciones neoliberales, sino también por la concepción del tiempo de estos cristianos, por pasajes bíblicos milenarios y por una constitución no moderna.

Para ser claros: existen innumerables conexiones entre el pentecostalismo y el neoliberalismo. Sin embargo, poner toda la atención en esos vínculos no explica satisfactoriamente el apoyo de los pentecostales hondureños al derrocamiento de Zelaya o su recalcitrante oposición a la izquierda. Además, tal análisis falla al considerar cómo la "política" en esta región se está haciendo múltiple (o quizás, bajo el radar moderno, siempre lo ha sido) tanto en la derecha como en la izquierda.

Para los pentecostales, a diferencia de la política moderna basada en la constitución, las interacciones de Dios con los humanos nunca se han ceñido al "corazón de corazones". De hecho, en el contexto de una geopolítica del espíritu Dios es un aliado indispensable para las luchas políticas. Pero su apoyo nunca está garantizado: Dios nunca intervendría contra su propia ideología política. La noción de que Dios tiene una ideología política podría sonar discordante para aquellos que, incluso si no son cristianos, consideran que la teología cristiana pone a Dios "por encima" de la política. Si bien este es el caso de muchos cristianos en el mundo, no es la teología de los cristianos con los que trabajé. Para ellos, Dios es indiscutiblemente de derecha, o mejor, la ideología de derecha está alineada con sus deseos para la humanidad. La noche del grupo de estudio bíblico esta perspectiva se hizo evidente cuando Nelson describió la preocupación del liderazgo de la iglesia a que un gobierno de izquierda pusiera a Honduras en contra de los caminos de Dios. Semanas después del golpe, el pastor del grupo dio un sermón en el que describió su concepción de la política de Dios en términos incluso más severos: “Dios les dice a aquellos que están a su lado derecho, Él les dice: 'vengan conmigo'. Pero los del lado izquierdo, esos son descartados. Dios no comulga con eso. ¿De qué lado vas a estar tú?".

Junto con la poca voluntad de Dios para oponerse a su propia ideología política, se entiende que la posibilidad de que Él intervenga en una lucha política depende de la cantidad de favores acumulados por quienes piden su apoyo. Incluso cuando se 
trata de causas que resuenan con la política de derecha de Dios, se dice que está más dispuesto a atender a aquellos que han acumulado favores con él. Para los cristianos, el favor se puede acumular de varias maneras: la oración, el diezmo (donando el $10 \%$ de los ingresos a la iglesia), el comportamiento moral adecuado y la lectura de la Biblia. No obstante, como a menudo escuché en los sermones, en los grupos de estudio bíblicos y en las conversaciones informales, la fuente más potente de favor es actuar en nombre de los judíos, especialmente de Israel.

Para entender por qué estos cristianos consideran el apoyo a los judíos (entre lo que cuenta la oración en su nombre) una fuente poderosa de favor divino, es preciso darle mayor atención al sionismo cristiano. Para estos pentecostales el favoritismo de Dios se extiende no solo a una ideología específica sino también a un pueblo específico: los judíos. La Biblia, en su lectura literal y dispensacionalista, contiene dos narrativas principales: una sobre los cristianos y otra sobre el "pueblo elegido de Dios". En su interpretación, el pacto establecido entre Dios y Abraham (el primer judío), en el cual Dios le prometió hacer de sus descendientes el "pueblo elegido", es eterna y no se puede romper nunca (Génesis 17: 3-7).

Debido a que son el "pueblo elegido", los cristianos sionistas insisten en que los judíos reciban las bendiciones divinas independientemente de si se adhieren o no a la voluntad de Dios. Para ellos, los judíos son bendecidos por lo que son, no por lo que hacen (Génesis 12: 2). Según los cristianos sionistas, este favor divino ha creado la inventiva, la riqueza y la influencia distintiva de los judíos, y se supone que dicho carácter judío tiene consecuencias geopolíticas puntuales. Los cristianos sionistas sostienen que esos atributos han puesto a Israel en el camino hacia convertirse, muy pronto, en la superpotencia global dominante, un punto de vista que coincide con la profecía dispensacionalista según la cual Israel se levantará como la potencia hegemónica global durante los Últimos Días.

Para estos cristianos, los gentiles, como ellos, pueden aprovechar esta fuente poderosa de favor divino actuando de maneras que benefician al "pueblo elegido". Una vez más, ubican esta posibilidad en la Biblia. Dios, en su promesa de hacer de los judíos un gran pueblo, declara: "Bendeciré a los que te bendijeren, y a los que te maldijeren maldeciré" (Génesis 12: 2). Durante mi trabajo de campo el esfuerzo en bendecir a los judíos para acumular el favor divino adoptó diversas formas: desde circular peticiones que exigían que el gobierno hondureño le brindara a Israel un mayor apoyo diplomático hasta una tremenda hospitalidad con los turistas judíos. Sin embargo, la manera más común era orar por Israel. Las oraciones del grupo de estudio bíblico de aquella noche fueron parte de su esfuerzo geopolítico para construir un favor con Dios y que así, de acuerdo con su constitución no moderna, interviniera en la política hondureña y trajera la paz que deseaban.

Los esfuerzos combinados -seculares y del espíritu- de estos cristianos por bendecir al pueblo judío resaltan un aspecto decisivo de la constitución no moderna 
de los pentecostales. La geopolítica del espíritu no establece una clara distinción ontológica entre la política convencional y la política del espíritu. Se entiende que las dos funcionan de maneras diferentes, y los pentecostales creen que la forma más efectiva de acción es la oración, pero no los consideran reinos ontológicos diferentes. Pese a que muchos pentecostales en Copán buscan con esmero el apoyo político de Dios, no niegan que las acciones políticas modernas (votaciones o peticiones, por ejemplo) y los actores modernos (como los movimientos sociales ciudadanos) ayudan a lograr sus objetivos. Por ejemplo, un comité local que organizó una manifestación para respaldar el golpe, acción política convencional que se convertiría en una de las más significativas inmediatamente después la expulsión de Zelaya, estaba compuesto, en casi su totalidad, por pentecostales. Pero la participación política convencional de los pentecostales no se limitó a Copán. De hecho, aunque la cobertura nacional e internacional de noticias seculares no los resaltó, muchos pentecostales de Copán me informaron que sus correligionarios marcharon por todo el país en manifestaciones a favor del golpe. Lo que en las noticias y en los reportes académicos se mostró como una fuerza política única y separada, podría describirse mejor como "dos mundos parcialmente conectados" (De la Cadena, 2010, 355).

\section{Mundos parcialmente conectados}

En los días de mi trabajo de campo los periódicos hondureños solían publicar mapas codificados por colores para representar la ideología política que guiaba al Estado de cada país latinoamericano: rojo para la izquierda y azul para la derecha. Para aquel entonces, entre el mar rojo de mapas estaban todos los países que tienen frontera con Honduras. Visto en retrospectiva, el 2009-2010 pudo haber sido el momento donde la marca agua de la "marea rosa" estuvo más resaltada.

Los mapas en los periódicos que ojeaba, mientras pasaba tiempo con copanecos, casi siempre incitaban a reaccionar fuertemente. Quienes apoyaban el golpe, tanto pentecostales como no pentecostales, expresaban sus preocupaciones respecto a que las corrientes de izquierda de la región pronto se tomarían Honduras. Haciendo eco de los alegatos emitidos en medios de comunicación del país, casi todos de derecha, y del gobierno de Micheletti, insistían en que un gobierno de izquierda marcaría el fin de la democracia en Honduras, y explicaban que cualquier presidente de izquierda sería, en última instancia, un títere controlado por Chávez. Aunque no fue muy común, algunos copanecos llegaron a describir el temor que tenían a que un gobierno de izquierda totalitario se apoderara de todas las propiedades privadas del país o les arrebatara a los niños a sus padres para reeducarlos.

Esas acusaciones, además de ser replicadas en espacios seculares, se materializaron en sermones en las tres iglesias a las que solía asistir. Por ejemplo, no mucho después del golpe, un pastor dio una visión aterradora del futuro del país en caso de 
que llegara a gobernar otro presidente de izquierda. Parado detrás del púlpito, insistió en que esta persona implementaría un programa, uno que supuestamente Chávez ya había instituido en Venezuela, que permitiría que el Estado capturara a todos los niños mayores de tres años. Mientras imitaba a alguien que golpeaba la puerta, explicaba que un representante del gobierno llegaría a tu casa en el tercer cumpleaños de tus hijos y declararía: “¡esos niños nos pertenecen!”. A unas pocas filas de donde yo estaba, noté cómo un padre ponía su brazo alrededor de su hijo pequeño. El pastor luego afirmó que, a partir de ese momento, el niño reclutado solo podría visitar a sus padres dos días al mes y que el Estado sería completamente responsable de su "educación física y mental".

Para muchos partidarios del golpe, el exilio de Zelaya retrasó temporalmente que el país se sumiera en algo como una pesadilla totalitaria, pero sostuvieron que esta victoria era provisional y que podría revertirse fácilmente. A veces, describían que la mayor amenaza era una izquierda renovada que emergía desde el interior de Honduras, por ejemplo, a través del FNRP. Sin embargo, más a menudo, veían que esos peligros afuera del espacio nacional: en las secciones rojas de los mapas. En las semanas posteriores al golpe, el ejército venezolano fue caracterizado como la fuerza externa más amenazadora, pero agregaban que el ejército de Chávez necesitaba ayuda de alguno de los vecinos de Honduras para poner en marcha una invasión. Hubo consenso sobre Nicaragua como el escenario más probable para tales acciones. A medida que pasaba el tiempo, y que el ejército venezolano retrocedía como una amenaza externa, los partidarios del golpe comenzaron a expresar su preocupación por la sombría presencia de agentes extranjeros que ingresaban a Honduras. De hecho, durante nuestras conversaciones a menudo se citaban los medios de comunicación de derecha, y las afirmaciones de la administración Micheletti, de que nicaragüenses y venezolanos habían instigado las protestas del FNRP.

Sin embargo, para la mayoría de los copanecos que apoyaban el exilio de Zelaya, el expresidente mismo era el actor externo cuyo potencial (re)ingreso al país provoca la mayor preocupación. Temían que, si Zelaya regresaba, asumiría nuevamente la presidencia sin necesidad de ocultar (lo que consideraban) sus verdaderas intenciones autoritarias, o iniciaría una guerra civil. De hecho, Zelaya hizo dos intentos infructuosos para regresar a Honduras. Finalmente entró al país el 21 de septiembre. Apareció, aparentemente de la nada, en la embajada brasileña en la capital hondureña. Permaneció allí dos meses, seguro de que si abandonaba el edificio sería arrestado.

Este marco geopolítico de derecha y pro-golpe tenía una contraparte del espíritu. La división política regional entre izquierda y derecha, que se superpone de muchas maneras, para muchos de los pentecostales no se desarrolló dentro del tiempo secular vacío, sino de acuerdo con la línea de tiempo dispensacionalista. Recordemos 
que, en su narrativa de los Últimos Días, las naciones del mundo se dividirán en dos bandos preparados para una batalla final entre las fuerzas de la luz (guiadas por el regreso de Jesús) y la oscuridad (guiadas por Satanás). Cuando los pentecostales miraban los mapas pintados de rojo y azul, era eso "lo [que estaba siendo] visto".

$\mathrm{Al}$ igual que otros partidarios del golpe, los pentecostales estaban preocupados por la permeabilidad de las fronteras nacionales: les preocupaba el ejército venezolano, los intrusos sombríos y el posible regreso de Zelaya. Pero también les preocupaba que agentes demoníacos entraran a Honduras. Durante un servicio, un pastor llamó a su congregación para pedirle a Dios: “Señor, haz una cerca de ángeles allí en las fronteras. Señor, haz una cerca de ángeles allí en la frontera con Nicaragua, allí a lo largo de El Salvador y aquí a lo largo de Guatemala".

Explicó que tal cerca evitaría que los enemigos espirituales de Honduras ingresaran al país a través de las naciones de izquierda -y por lo tanto demoniacas- que rodeaban a Honduras.

Las similitudes entre la geopolítica secular y la del espíritu -la preocupación por las fronteras nacionales y las marcadas divisiones binarias entre amigos/enemigos, derecha/izquierda y democracia/totalitarismo- vuelve muy tentador reducir la última a la primera, es decir, imaginar que la geopolítica del espíritu simplemente se viste con una ideología secular de derecha armada con lenguaje e imágenes cristianas. Rastrear los hilos genealógicos de esta geopolítica de derecha quizá fortalecería este impulso reduccionista. Muchos de los tropos compartidos por la geopolítica secular y la del espíritu se volvieron hegemónicos en Honduras durante las luchas de la Guerra Fría de los ochenta. En ese momento, el Estado hondureño, la élite nacional y los Estados Unidos promovieron al país como un baluarte del capitalismo y la democracia contra las fuerzas de izquierda de la región (las guerrillas de El Salvador y Guatemala y el gobierno sandinista de Nicaragua). Pero era un baluarte vulnerable a un "enemigo interno" (la izquierda hondureña) y a una "amenaza externa" (los sandinistas) (Salomón). Ambos tipos de enemigos, insistían los gobiernos de Estados Unidos y Honduras, se empeñaban en transformar a Honduras en el próximo Estado totalitario dominado por extranjeros.

Si la investigación parara aquí, se podría argumentar que la parte "del espíritu" de la geopolítica del espíritu es una fachada que cubre una geopolítica secular revivida de la Guerra Fría. No obstante, sugiero que el cristianismo y la geopolítica secular se pueden entender mejor como mundos "parcialmente conectados". Como sugiere De la Cadena, citando a Strathern, tales mundos "no son ni singulares ni plurales, ni uno ni muchos, son un circuito de conexiones antes que partes puestas juntas" (54). Para el caso de los mundos indígenas y no indígenas de los Andes, De la Cadena emplea la figura de "conexiones parciales" para articular cómo "prácticas que pueden ser llamadas indígenas y no-indígenas se infiltran y emergen entre sí" $(2015,5)$ y son "partes integrales las unas de las otras" $(2015,161)$. 


\section{Cristianismo y geopolítica de la Guerra Fría}

Examinar la supuesta secularidad de la Guerra Fría sirve para poner de manifiesto esta conexión. En los Estados Unidos, varios devotos protestantes de línea principal, con experiencia misionera o pastoral, jugaron un papel clave en la articulación del marco geopolítico al principio de la Guerra Fría. Su fe protestante estaba en el corazón de las descripciones que hicieron de la Guerra Fría en términos binarios estrictos ("civilización cristiana" contra "comunistas sin Dios" o una "guerra santa" contra los no-religiosos), y parte de la batalla era por las "almas de los hombres", en la cual no había término medio (Foglesong; Kirby).

Durante la administración Reagan (1981-1989), particularmente, el Estado secular y los cristianos evangélicos coprodujeron la geopolítica de la Guerra Fría de los Estados Unidos de muchas maneras. Este trabajo geopolítico colaborativo fue muy evidente en Centroamérica. Como dijo Grandin: “Centroamérica... fue el crisol que juntó al cristianismo misionero, al capitalismo de libre mercado y al duro poder estadounidense" (155-156). Esta coproducción fue, en gran parte, discursiva. Tanto en los Estados Unidos como en Centroamérica, muchos cristianos evangélicos articularon y reforzaron una división maniquea hemisférica entre la izquierda y la derecha: la primera relacionada con el ateísmo, la dominación extranjera, el socialismo y el totalitarismo y, la segunda, con el cristianismo, la libertad, el capitalismo y la democracia. Este grupo de ideas asociadas se dispersaron a través de muchos medios: los sermones y libros de televangelistas populares, como Jerry Falwell y Pat Robertson, el proselitismo de un grupo de misioneros evangélicos estadounidenses en Centroamérica, y los avivamientos masivos en la región, a cargo de pastores prominentes que viajaban desde Estados Unidos (Grandin; Stoll).

Pero esos esfuerzos geopolíticos entrelazados ni se limitaron al discurso ni se constriñeron a las fronteras convencionales entre organizaciones religiosas y Estados seculares. De hecho, las instituciones evangélicas estadounidenses con presencia en Centroamérica actuaron casi siempre de maneras que suelen pertenecer al ámbito de los Estados seculares. Por ejemplo, dieron ayuda a los gobiernos de derecha en Guatemala y en El Salvador y a los Contras (Grandin; Stoll). La Embajada Cristiana Internacional en Jerusalén (ICEJ), una organización dispensacionalista y sionista cristiana que brindó ayuda a los Contras, llegó a tener "embajadas" en Honduras y Guatemala. Los miembros del ICEJ recibieron estatus diplomático oficial en ambos países y permiso para importar dinero y bienes sin inspección alguna (Wagner 109).

La retórica y las actividades de la derecha religiosa en la región no deberían verse como meras extensiones de la administración Reagan. Los sentimientos anti-izquierda de los dispensacionalistas se remontan a antes de la Primera Guerra Mundial. Por mucho tiempo se han opuesto al socialismo, el comunismo y cualquier intento de mejorar la condición del mundo caído que no eche sus raíces en el poder de Dios y en 
una línea de tiempo predeterminada (Marsden). Dicho de otra manera: la oposición de los dispensacionalistas a la izquierda no solo tiene su propia trayectoria histórica (que no está aislada), sino que su ontología ha sido fundamental en la producción de su hostilidad hacia la izquierda. En el "mundo que vieron" solo Dios podía transformar las cosas para mejor y, por tanto, cualquier intento de hacerlo que se enraice en la voluntad corroída de la humanidad, o en un calendario arbitrario, terminará en la ruina.

En el trabajo de campo me hice una idea muy general sobre los enredos entre la geopolítica evangélica y la secular de la Guerra Fría en la región, pero había asumido que cualquier vínculo entre Honduras e Israel era producto de la ideología cristiana sionista. Sin embargo, las conexiones seculares entre los dos países pronto aparecieron en los titulares nacionales. Unos días después del golpe, Micheletti anunció en una conferencia de prensa que el gobierno israelí apoyaba su presidencia. Yo descubriría más tarde que el gobierno israelí nunca reconoció oficialmente esa administración. Micheletti, o mintió durante la conferencia de prensa o hizo público lo que estaba destinado a permanecer en privado. La verdad nunca se supo, pero me impresionó que todos, incluso los pentecostales, encontraran lógico ese insustancial apoyo político israelí al gobierno de derecha Micheletti.

Comencé a recapitular pedazos de conversaciones tenidas en el pasado con los copanecos sobre Israel, en las cuales no había pensado mucho hasta ese momento. Aunque los comentarios no fueron hechos por pentecostales, compartían el entusiasmo de los sionistas cristianos por Israel, pues invocaban las mismas nociones sobre una supuesta inventiva, modernidad y riqueza judías. Por ejemplo, dos amigos que compararon el desarrollo económico de Israel y Honduras, notaron que, si bien Israel era un país mucho más joven que Honduras, y carecía de sus recursos naturales, se había desarrollado más rápidamente. Además, años antes de escuchar el término "sionismo cristiano", un día que salí con algunos copanecos a un bar, mi amigo Marcos se desvío de una extendida perorata sobre su tema favorito, el ejército, para declarar: "Los judíos en Israel son increíbles. Pueden tomar un arma de cualquier lado y mejorarla. Son tan inteligentes".

Solo cuando investigué la historia de las conexiones entre Israel y Honduras, pude poner esos comentarios en un contexto más amplio. El apoyo israelí a un gobierno de derecha en la región tenía sentido, una vez más, debido a las alianzas de la Guerra Fría de los ochenta. Israel, y particularmente el ejército israelí, tuvo un impacto sustancial en la región durante esa sangrienta década, en la que proporcionó armas, asesores, equipo logístico y entrenamiento militar a regímenes de derecha en Honduras, Nicaragua, El Salvador, Guatemala y los Contras (Jamail y Gutiérrez 34). Entre otros factores, la presencia de Israel en Centroamérica durante este período fue el resultado de su posición dentro de la geopolítica imaginaria, pero también real, de la Guerra Fría. El gobierno israelí veía a los posibles gobiernos de izquierda de Centroamérica como potenciales aliados de la Organización de Liberación de Palestina. De hecho, 
la Nicaragua sandinista se había convertido en aliada. La alianza de Israel con los Estados Unidos, junto a todo lo demás, la ubicó, firmemente, en el lado "anticomunista", "democrático" del binario de la Guerra Fría (Jamail y Gutiérrez 7).

Estas imbricaciones entre la ideología cristiana sionista y la geopolítica secular de Israel y Honduras revelan un "circuito de conexiones" (Strathern 54) que viajan a través de este mundo parcialmente conectado. El sionismo cristiano y la geopolítica secular no son idénticos, pero se superponen en gran medida formando una entidad que no es "ni una ni muchas" (Strathern). Apenas unos días después de su llegada a la embajada de Brasil, Zelaya dio nuevas evidencias de la dimensión secular de este mundo parcialmente conectado. En una entrevista con un periodista del Miami Herald, informó que "mercenarios israelíes" lo estaban torturando a él y a otros en la embajada con "radiación de alta frecuencia" (Robles).

Para la mayoría de los copanecos con los que hablé (tanto pentecostales como no pentecostales), la participación de Israel en el después del golpe era perfectamente plausible, aun cuando la afirmación de Mel sobre su papel no era precisa en todos los detalles. De hecho, no mucho después de que los medios hondureños divulgaran los comentarios de Zelaya, tuve una cena informal con David y Enrique, importantes miembros de la iglesia pentecostal. A mitad de la comida, les pregunté qué pensaban sobre lo dicho por Mel. Explicaron que, según su pastor, militares hondureños, no mercenarios israelíes, llevaron a cabo estos ataques. Israel simplemente había proporcionado el equipo. David agregó que la entrega de esta tecnología ni siquiera era la más importante de las acciones que Israel estaba tomando en nombre de Honduras. David reveló, y Enrique asintió, que la mayor contribución de Israel provino de su servicio de inteligencia, que dio información clave al gobierno de Honduras sobre los esfuerzos de los agentes venezolanos y nicaragüenses para ingresar al país.

\section{Conclusión}

Como, espero, queda claro en este punto, desacelerar nuestro pensamiento para prestar atención a la ontología del espíritu de los pentecostales después del golpe de Estado de Honduras, de 2009, no da una versión más esperanzadora (al menos desde mi perspectiva de izquierda) sobre un oculto potencial progresista en las iglesias pentecostales de Copán (Burdick). Si tal potencial existe, no lo encontré. Pero centrarse en la ontología política de los pentecostales en este contexto permite poner de relieve las consecuencias "políticas" que los mundos que habitan estos cristianos, y cómo los inquilinos del mundo del espíritu desbordan los límites de la "política". Tomarse en serio los mundos pentecostales facilita una mayor comprensión de las razones por las que a menudo se oponen a los gobiernos de izquierda, o que tienden a la izquierda, y llaman la atención sobre los múltiples "mundos que están siendo vistos" (Viveros de Castro) en la Latinoamérica contemporánea. 
El análisis De la Cadena de las ontologías políticas indígenas de izquierda aplicado a las ontologías pentecostales de derecha interrumpe nuestra propia "geografía de la ontología". Tal geografía tiende a imaginar que la ontología moderna se ubica dentro de Norteamérica y Europa (urbanas), y las ontologías no modernas en África, Asia y Latinoamérica (rurales). Pero las ontologías no modernas del pentecostalismo, y sus predecesoras, se desarrollaron en los Estados Unidos y Gran Bretaña, y han florecido allí -a menudo en espacios urbanos- durante siglos.

Finalmente, la geopolítica del espíritu complica la tendencia antropológica a celebrar las ontologías no modernas y asociarlas con la resistencia política. Esta tendencia surge por buenas razones. Gran parte de la fuerza académica se ha centrado en los pueblos indígenas, cuyas ontologías han perdurado a pesar de los siglos de la Iglesia y de la corona, y de los esfuerzos de los Estados nacionales por eliminarlos. Sin embargo, situar a los pentecostales en la discusión sobre Latinoamérica destaca que la política imbricada con las ontologías no modernas no tiene un fin político intrínseco. Tales proyectos pueden superponerse con la derecha o con la izquierda, con la dominación o con la resistencia.

\section{Notas}

1 Este rango sale de varias fuentes: de las estimaciones de los Copanecos, de las estimaciones de los pastores pentecostales de Copán sobre del tamaño de sus congregaciones, y de encuestas de opinión realizadas en Honduras entre 2005 y 2012 (Holland). Todos esos métodos tienen límites, pero los resultados están en ese rango de diez puntos.

2 Reproducido, con el permiso de la Asociación Americana de Antropología, de The Journal of Latin American and Caribbean Anthropology, Volumen 24, Número 1, pp. 162-180, 2019. No está permitida su venta ni su reproducción posterior. El artículo original puede encontrarse en https://doi.org/10.1111/jlca.12342. La traducción fue realizada por Sonia Serna Botero.

3 La guerra espiritual no solo se libra internacionalmente sino también en la escala local o nacional. Por ejemplo, los pentecostales en Copán suelen enfocarse en las ruinas mayas locales, pues insisten en que son un lugar especialmente intenso para la actividad demoníaca.

Los "actores extraños" de las ontologías indígenas no son idénticos a los "actores extraños" de las ontologías pentecostales. Hay innumerables diferencias entre ellos. Para obtener excelentes relatos de estas diferencias en los Andes, ver De la Cadena (2015, 95-96) y Canessa (57-62).

Ver también Reichman (121-122).

Ver también Pine y Reichman (122).

Me concentro aquí en la línea académica que designa el "neoliberalismo" como un asunto central de la relación entre pentecostales y política en la región, y no tengo en cuenta otra literatura sobre pentecostalismo y política en Latinoamérica que va más allá del marco "opio/individualización". Por ejemplo, Brenneman (242-244) critica los enunciados de Pine sobre la individualización pentecostal, afirmando que este modo de autoconstrucción puede condensar "una conciencia crítica y un movimiento por la justicia económica y social" (224). 
Por su lado, el estudio de Burdick (119-147) sobre mujeres pentecostales negras en Brasil hace un recuento etnográfico de los sorprendentes rumbos políticos que pueden tomar los proyectos pentecostales de individualización. Además, Smilde describe la autodisciplina pentecostal como una "forma de agencia cultural a través de la cual [los adherentes] pueden tener control sobre aspectos de su contexto personal y social" (5), como la adicción, el machismo y la violencia. Mientras reconoce que las iglesias pentecostales proporcionan estos "bienes sociales colaterales", Garrard-Burnett argumenta que tales actividades no son propiamente "políticas". Sin embargo, señala una serie de proyectos pentecostales emergentes en Centroamérica que, debido a su compromiso con la justicia social, considera "políticos". Finalmente, el trabajo reciente de $\mathrm{O}^{\prime} \mathrm{Neill}$ (2015) examina no solo lo que el pentecostalismo encubre, sino también las "las condiciones para la visibilidad, la segregación y el cautiverio" (11) que establece. También hay una vibrante literatura sobre la relación entre el pentecostalismo y la política más allá de Latinoamérica. Ver, por ejemplo, Haynes y Marshall.

\section{Bibliografía}

Anderson, Benedict. Imagined Communities: Reflections on the Origin and Spread of Nationalism. New York: Verso, 1991.

Brenneman, Robert. Homies and Hermanos: God and Gangs in Central America. New York: Oxford University Press, 2011.

Burdick, John. Blessed Anastácia: Women, Race, and Popular Christianity in Brazil. New York: Routledge, 1998.

Canessa, Andrew. Intimate Indigeneities: Race, Sex, and History in the Small Spaces of Andean Life. Durham, NC: Duke University Press, 2012.

De la Cadena, Marisol. Indigenous Cosmopolitics in the Andes: Conceptual Reflections Beyond Politics. Cultural Anthropology 25, 2(2010): 334-70.

De la Cadena, Marisol. Earth Beings: Ecologies of Practice across Andean Worlds. Durham, NC: Duke University Press, 2015.

Escobar, Arturo. Latin America at the Crossroads: Alternative Modernizations, PostLiberalism, or PostDevelopment? Cultural Studies 24, 1(2010): 1-66.

Foglesong, David S. Roots of "Liberation": American Images of the Future of Russia in the Early Cold War, 1948-1953. International History Review 21, 1(1999): 57-79.

Garrard-Burnett, Virginia. Towards a Pentecostal Hermeneutics of Social Engagement in Central America? Bridging the Church and the World in El Salvador and Guatemala. En New Ways of Being Pentecostal in Latin America, editado por Martin Lindhardt, 187208. Lanham, MD: Lexington Books, 2016.

Grandin, Greg. Empire's Workshop: Latin America, The United States, and the Rise of the New Imperialism. New York: Owl Books, 2006.

Haynes, Naomi. “Zambia Shall be Saved!”: Prosperity Gospel Politics in a Self-proclaimed Christian Nation. Nova Religio: The Journal of Alternative and Emergent Religions 19, 1(2015): 5-24.

Holland, Clifton. Public Opinion Polls on Religious Affiliation in Honduras, 1997-2012. PROLADES. Recuperado de http://www.prolades.com/cra/regions/cam/hon/ hon polls 1997-2012.pdf

Jamail, Milton H. y Gutiérrez, Margo. It's No Secret: Israel's Military Involvement in Central America. Belmont, MA: Association of Arab-American University Graduates, 1987.

Kirby, Dianne. Religion and the Cold War. New York: Palgrave, 2003. 
Latour, Bruno. We Have Never Been Modern. Translated by Catherine Porter. Cambridge, MA: Harvard University Press, 1993.

Marsden, George. Fundamentalism and American Culture: The Shaping of Twentieth-Century Evangelicalism, 1870-1925. New York: Oxford University Press, 1980.

Marshall, Ruth. Political Spiritualties: The Pentecostal Revolution in Nigeria. Chicago, IL: University of Chicago Press, 2009.

O'Neill, Kevin. City of God: Christian Citizenship in Postwar Guatemala. Berkeley, CA: University of California Press, 2010.

O'Neill, Kevin. Secure the Soul: Christian Piety and Gang Prevention in Guatemala. Berkeley, CA: University of California Press, 2015.

Pine, Adrinne. Working Hard, Drinking Hard: On Violence and Survival in Honduras. Berkeley, CA: University of California Press, 2008.

Reichman, Daniel. 2011. The Broken Village: Coffee, Migrations, and Globalization in Honduras. Ithaca, NY: ILR Press, 2011.

Robles, Frances. They're Torturing Me, Honduras' Manuel Zelaya Claims. Miami Herald, 2009.

Salomón, Leticia. The National Security Doctrine in Honduras: Analysis of the Fall of General Álvarez Martínez. En Honduras: Portrait of a Captive Nation, editado por Nancy Peckenham and Annie Street, 197-207. New York: Praeger, 1984.

Smilde, David. Reason to Believe: Cultural Agency in Latin American Evangelicalism. Berkley, CA: University of California Press, 2007.

Stoll, David. Is Latin America Turning Protestant? The Politics of Evangelical Growth. Berkley, CA: University of California Press, 1990.

Strathern, Marilyn. Partial Connections. New York: Altamira, 2004.

Viveros de Castro, Eduardo. Perspectival Anthropology and the Method of Controlled Equivocation. Tipit' 1 : Journal for the Society of Lowland South America 2, 1(2004): 3-22.

Wagner, Donald E. Anxious for Armageddon: A Call to Partnership for Middle Eastern and Western Christians. Scottsdale, PA: Herald Press, 1995.

Weber, Max. The Protestant Ethic and the "Spirit" of Capitalism and Other Writings. New York: Penguin Books, 2002 [1905].

William Girard. Estadounidense. Profesor visitante en Mount Holyoke College, Estados Unidos. Ha impartido clases en Amherst College y Hampshire College. Girard tiene un doctorado y una maestría en Antropología Cultural de la Universidad de California en Santa Cruz, y una maestría en Estudios Religiosos de la Universidad de Chicago. Sus investigaciones han sido financiadas por la fundación Wenner-Gren y por el programa Fulbright-Hays.

Contacto: billgirard@gmail.com

ORCID: 0000-0002-6281-5892 